\title{
Diselenolane-Mediated Cellular Uptake: Efficient Cytosolic Delivery of Probes, Peptides, Proteins, Artificial Metalloenzymes and Protein-Coated Quantum Dots
}

\author{
Eline Bartolami, ${ }^{[a, c]}$ Dimitris Basagiannis, ${ }^{[a]}$ Lili Zong, ${ }^{[a, d]}$ Rémi Martinent, ${ }^{[a]}$ Yasunori Okamoto, ${ }^{[b, c]}$ \\ Quentin Laurent, ${ }^{[a, c]}$ Thomas R. Ward, ${ }^{[b, c]}$ Marcos Gonzalez-Gaitan, ${ }^{[a]}$ Naomi Sakai ${ }^{[a, c]}$ and Stefan \\ Matile $^{*[a, c]}$
}

\begin{abstract}
Cyclic oligochalcogenides are emerging as powerful tools to penetrate cells. With disulfide ring tension maximized, selenium chemistry had to be explored next to enhance speed and selectivity of dynamic covalent exchange on the way into the cytosol. We show that diseleno lipoic acid (DiSeL) delivers a variety of relevant substrates. DiSeL-driven uptake of artificial metalloenzymes enables bioorthogonal fluorophore uncaging within cells. Binding of a bicyclic peptide, phalloidin, to actin fibers evinces targeted delivery to the cytosol. Automated tracking of diffusive compared to directed motility and immobility localizes $79 \%$ of protein-coated quantum dots (QDs) in the cytosol, with little endosomal capture $(0.06 \%)$. These results suggest that diselenolanes might act as molecular walkers along disulfide tracks in locally denatured membrane proteins, surrounded by adaptive micellar membrane defects. Miniscule and versatile, DiSeL tags are also readily available, stable, soluble, and non-toxic.
\end{abstract}

We first experienced the power of thiol-mediated uptake ${ }^{[1,2]}$ when we replaced the peptide backbone of cell-penetrating peptides $(\mathrm{CPPs})^{[3]}$ with disulfide bonds in cell-penetrating poly(disulfide)s (CPDs). ${ }^{[4]}$ Their efficient entry into cells ${ }^{[5-7]}$ was shown to occur through dynamic covalent disulfide exchange ${ }^{[8]}$ with exofacial thiols on the cell surface..$^{[4,7]}$ This called for the application of ring tension, increasing from disulfide 1 to 5 (Figure 1A). ${ }^{[9-11]}$ In relaxed disulfides such as 1 , the CSSC dihedral angle is $90^{\circ}$ to minimize the lone pair repulsion and maximize hyperconjugation (Figure 1B). ${ }^{[12]}$ Maximal ring tension in ETPs 5 with a CSSC $\sim 0^{\circ}$ resulted in maximal uptake activity among disulfides containing compounds. ${ }^{[10]} \quad$ To enhance the activity of cyclic

[a] Dr. E. Bartolami, Dr. D. Basagiannis, Dr. L. Zong, R. Martinent, Q. Laurent, Dr. M. Gonzalez-Gaitan, Dr. N. Sakai, Dr. S. Matile National Centre of Competence in Research (NCCR) Chemical Biology

School of Chemistry and Biochemistry, University of Geneva, $\mathrm{CH}-1211$ Geneva, Switzerland

E-mail: stefan.matile@unige.ch

[b] Dr. Y. Okamoto, Dr. T. R. Ward Department of Chemistry, University of Basel

[c] National Centre of Competence in Research (NCCR) Molecular Systems Engineering $\mathrm{CH}-4002$ Basel, Switzerland

[d] Current Address: School of Chemistry and Chemical Engineering, Southeast University

Nanjing 210096, China

Supporting information for this article is given via a link at the end of the document. oligochalcogenides (COCs) further, replacement of sulfur by selenium appeared most promising. Owing to the higher polarizability of selenium atoms, thiolate-diselenide exchange reactions are known to proceed faster than with disulfides. ${ }^{[2,13]}$ Indeed, already relaxed diselenides 6 were more potent transporters than disulfides $\mathbf{5}$ at maximal tension, and uptake efficiency further increased with tension in diselenolipoic acid (DiSeL) 7. ${ }^{[11]}$ Although the CXXC dihedral angle of diselenolane $\mathbf{7}$ is smaller than that of lipoic acid $\mathbf{3}\left(\sim 35^{\circ}\right)$, its ring tension is lower because the Se bonds are longer. ${ }^{[11]}$ Diselenide-mediated uptake nevertheless exceeds disulfide-mediated uptake because the higher polarizability increases exchange rates and selectivity, resulting in pronounced selenophilicity. ${ }^{[2,13]}$

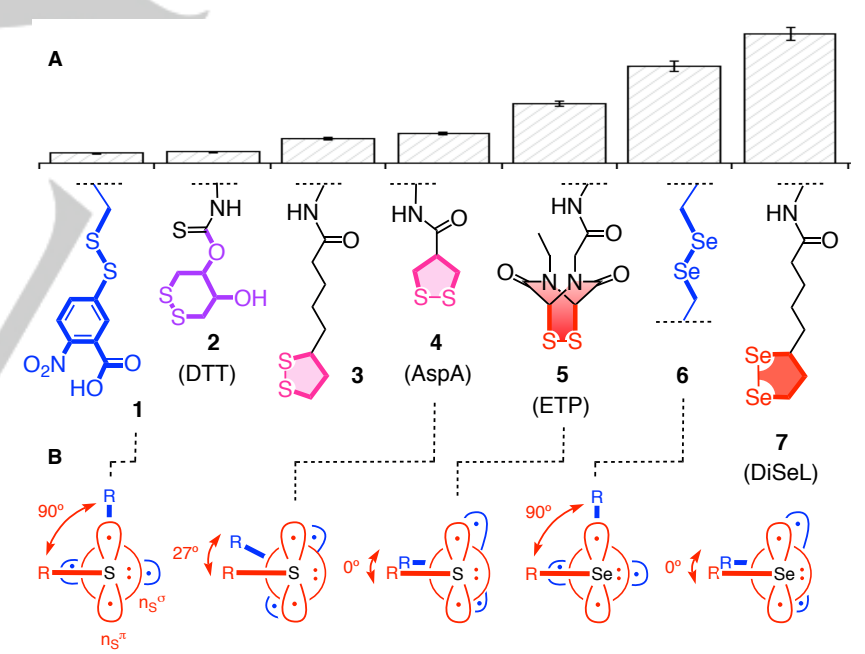

Figure 1. (A) Flow cytometry trends for uptake of fluorescein-labeled dichalcogenides 1-7 into HeLa Kyoto cells, ${ }^{[8-10]}$ with $(B)$ selected CXXC dihedral angles $(\mathrm{X}=\mathrm{S}$ or $\mathrm{Se})$

Uptake with acyclic diselenides 6 (and dithiolanes 3 and 4 ) suffers from endosomal capture probably because fast exchange with cell surface thiols results in stable selenosulfides. ${ }^{[11]}$ With DiSeL 7 (and ETPs 5), after reacting with cellular thiols, the proximal selenolates (and thiolates) remain deprotonated and thus reactive, assuring that the transporters can move on and hop along disulfides and thiols to avoid endosomal capture and enter into cytosol and nucleus. ${ }^{[11]}$ DiSeL-mediated uptake has been shown to be insensitive to common endocytosis inhibitors and non-toxic up to at least $100 \mu \mathrm{M} .{ }^{[11]}$ These results on COC-mediated cellular 
uptake have been obtained with fluorescein-labeled dichalcogenides 1-7 (Figure 1A). Preliminary results on biologically more relevant substrates are available only for AspA 4, which is weakly active and suffers from endosomal capture. ${ }^{[14]}$ Based on the unique characteristics found for diselenolanes, ${ }^{[11]}$ the objective of this study was to explore the compatibility of DiSeL-mediated uptake with larger substrates of biological relevance. Using mostly topics that have been developed recently to characterize the large CPD polymers, ${ }^{[5,6]}$ we here report that cellular uptake of the tiny diselenolanes is compatible with the cytosolic delivery of a broad variety of functional substrates with diameters up to $15 \mathrm{~nm}$. The combination of this broad substrate tolerance with insights from model studies call for a mode of action that envisions DiSeL as molecular walkers ${ }^{[15]}$ that move along disulfide tracks in transmembrane proteins, causing temporary local denaturation ${ }^{[16]}$ and the appearance of adaptive micellar membrane defects. ${ }^{[17]}$

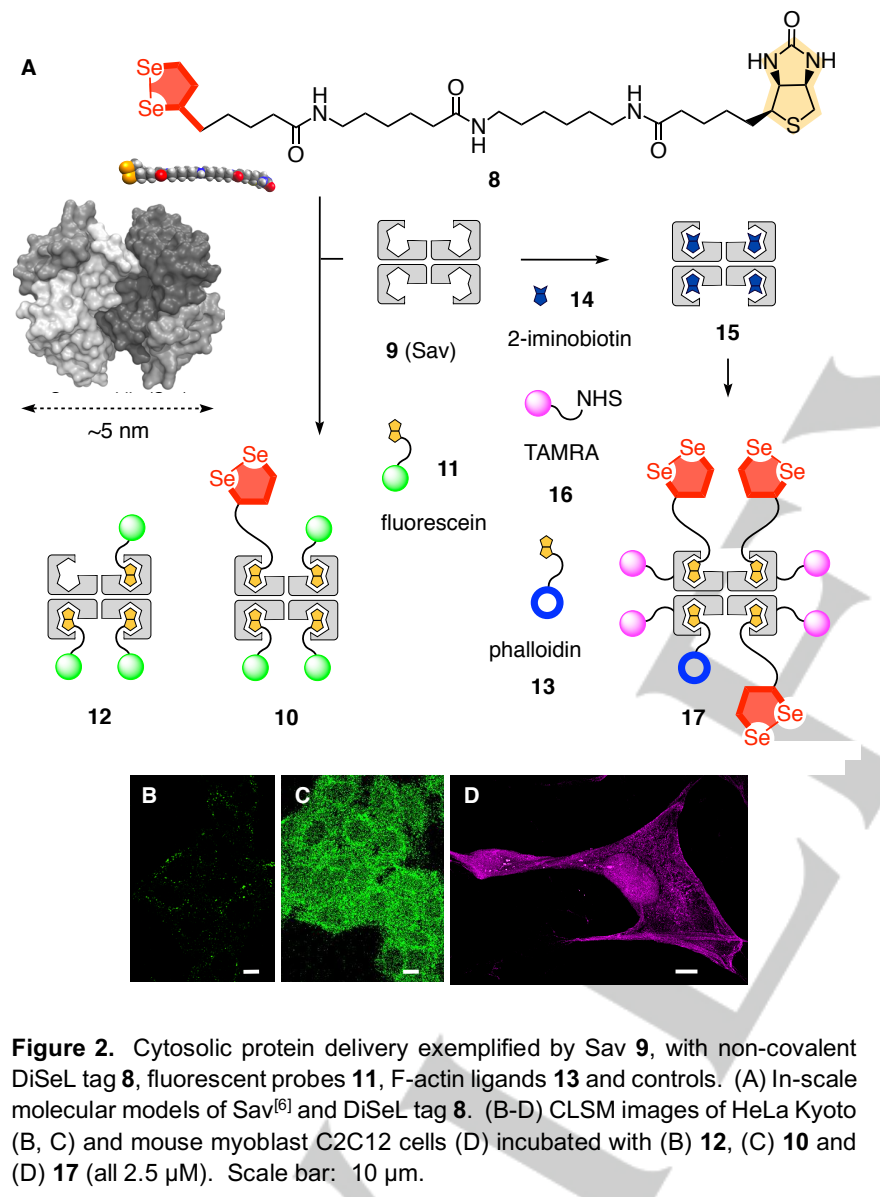

The biotinylated DiSeL tag 8 was synthesized ${ }^{[18]}$ for general noncovalent connection to the substrate through the tetravalent streptavidin (Sav) 9, a $\sim 60 \mathrm{kDa}$ protein (Figure 2)..$^{[5,6,19]}$ Complexes 10 were prepared by mixing Sav 9 with biotinylated fluorophores 11 and biotinylated DiSeL tag 8 in a 3:1 ratio. All complex stoichiometries given in the following refer to mixing ratios, real existing product mixtures are naturally more complex. ${ }^{[5,6,19]}$ The complexes $\mathbf{1 0}$ were efficiently taken up into HeLa Kyoto cells (Figure 2C), while control complexes 12 without DiSeL tag 8 were inactive (Figure 2B). Analogous complexes prepared with biotinylated AspA and ETP tags gave clearly weaker uptake efficiency (Figures S1, S2). Cellular uptake of complex $\mathbf{1 0}$ was observed in all tested, overall four other cell lines (Figures 2, S3).

Biotinylated phalloidin 13 was selected next as a functional substrate to be delivered in the cytosol. Phalloidin is a toxic bicyclic heptapeptide from death cap mushrooms that specifically binds to and prevents the depolymerization of actin fibers. ${ }^{[20]}$ To facilitate the formation of trifunctional Sav conjugates with the targeting unit 13, transport unit 8 and the fluorescent reporter, Sav 9 was covalently modified by tetramethyl rhodamine (TAMRA) fluorophores. The biotin binding sites were protected first with the weakly bound 2-iminobiotin $14^{[21]}$ to give complex 15 , which in turn was reacted with the NHS-activated TAMRA $16 .{ }^{[18]}$ The resulting red-fluorescent Sav was then loaded with the DiSeL tag 8 and phalloidin 13 in a 3:1 ratio. Added to mouse myoblast $\mathrm{C} 2 \mathrm{Cl} 2$ cells, the resulting complex 17 efficiently tracked actin fibers, thus demonstrating DiSeL-driven delivery of functional proteins to the cytosol with high efficiency (Figures 2D, S6).
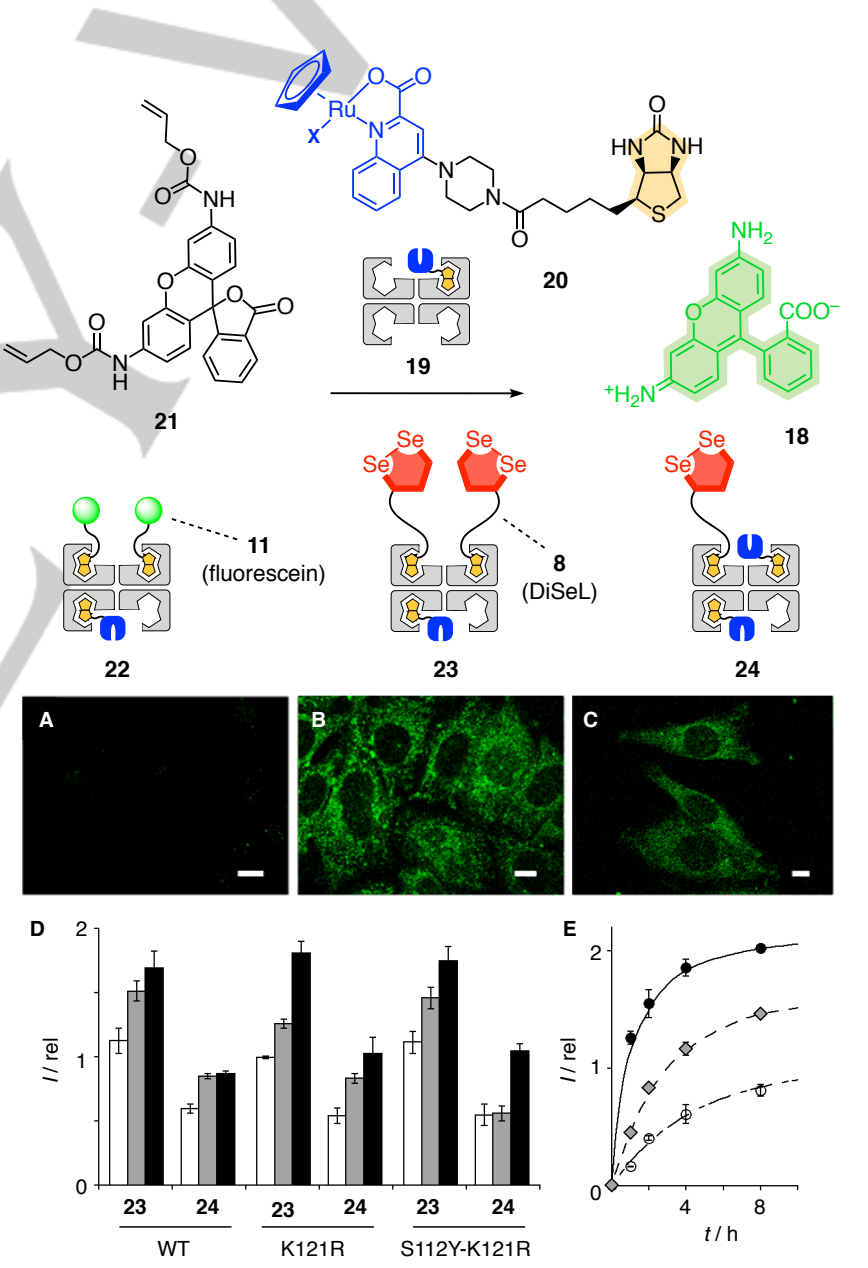

Figure 3. CLSM images of HeLa Kyoto cells incubated first with (A) 22, (B) 23 and (C) 24 (all $2.5 \mu \mathrm{M}$ ), then with substrate $21(10 \mu \mathrm{M})$. (D) Relative fluorescence intensities of cells treated with 23 and 24 (2.5: open, 5.0: grey or $10 \mu \mathrm{M}$ black bars; note, the concentrations of Ru catalysts are double in 24) composed of WT Sav, K121R or S112Y-K121R mutants. (E) Kinetics of the fluorescent product 18 formation in solution catalyzed by $23(10 \mu \mathrm{M})$ containing WT Sav (open circles), K121R (filled circles) or S112Y-K121R mutants (filled diamonds). 
The catalysis of bioorthogonal transformations by artificial metalloenzymes for metabolic engineering in designer cells is a topic of current concern that relies on efficient cytosolic delivery. ${ }^{[6]}$ We considered next the uncaging of fluorescent rhodamine 110 $(18)^{[22]}$ by the "deallocase" 19 , i.e., a Sav equipped with ruthenium complex $\mathbf{2 0}$ to catalyze the cleavage of Alloc groups in caged $\mathbf{2 1}$, to further elaborate on scope and limitations of DiSeL-mediated uptake (Figure 3).

Although the hydrophobic and non-fluorescent substrate $\mathbf{2 1}$ is known to spontaneously diffuse into cells, its addition after deallocase $\mathbf{2 2}$ did not result in the appearance of fluorescence in HeLa Kyoto cells from the product $\mathbf{1 8}$ or the probe in $\mathbf{2 2}$ (Figures $3 \mathrm{~A}, \mathrm{~S} 8$ ). These results suggest that the proteins failed to penetrate the cells. In clear contrast, the addition of the doubly DiSeLated but non-fluorescent deallocase $\mathbf{2 3}$ generated increasing emission from HeLa Kyoto cells with increasing concentration, demonstrating the bioorthogonal uncaging of $\mathbf{2 1}$ by the cell-penetrating metalloenzyme 23 (Figures 3B, S9). The deallocase showed efficient catalytic activity in all tested cell lines (Figure S10). Confirming the central importance of delivery for bioorthogonal catalysis within cells, the metalloenzyme $\mathbf{2 4}$ with higher stoichiometry of catalytic unit and lower stoichiometry of transporter unit showed lower activity (Figures 3C, 3D, S9, S11, Tables S1, S2). Further demonstrating the dominant contribution of cellular uptake, fluorophore uncaging in cells did not significantly depend on K121R and S112Y-K121R mutations ${ }^{[6]}$ of Sav (Figure 3D, Tables S1, S2), despite their different catalytic activities in solution (Figures 3E, S12-S14). According to the MTT assay, none of the tested DiSeLated metalloenzymes were toxic at $2.5 \mu \mathrm{M}$ (Figure S15). While the intracellular location of metalloenzymes could not be determined due to its invisibility, product 18 co-localized well with trackers of endosomes (PCC = $0.64 \pm 0.03)$ and mitochondria $(P C C=0.66 \pm 0.04$, Figure $S 16)$. Based on the similar localizations found previously with $18,{ }^{[22,23]}$ we speculate that the product formed in the cytosol freely diffuses to the organelles that have a natural propensity to accumulate it.

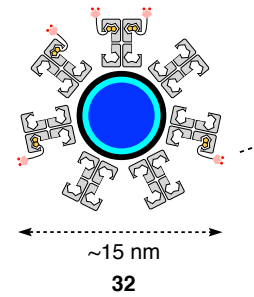

single frame

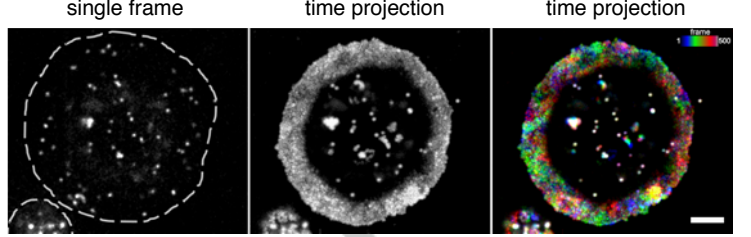

Figure 4. (A) Confocal images of live drosophila S2 cells treated with $6.66 \mathrm{nM}$ DiSeL-QD complex 25 (80:1 molar ratio). Left panel: Single confocal plane. Middle panel: Time projection of a movie captured from the cell shown on the left. Right panel: Time projection color-coded according to frame number ( $n=$ 500 frames, blue to violet, $5 \mu \mathrm{m}$ scale bar). (B) Quantitative analysis of shortrange QD tracks. Light blue area: Weighted mean square displacement as a function of delay time ( $n=6299$ tracks). Dashed dark blue line: Fit of subdiffusion model $\mathrm{MSD}(\mathrm{t})=4 D t^{\alpha}\left(R=0.998 ; D=0.150 \pm 0.001 \mu \mathrm{m}^{2} / \mathrm{s}, \alpha=0.627 \pm\right.$ $0.016 ; 95 \%$ confidence interval).
The delivery of large nanoparticles is promising for therapeutic purposes, but suffers from poor and not improving yields. ${ }^{[2]}$ The efficient cytosolic delivery of quantum dots (QDs) is considered particularly challenging, achieved usually by physical (electroporation, microinjection) but rarely by chemical methods, except with CPDs. ${ }^{[5]}$ However, DiSeL-QD complex 25, obtained by the addition of $\sim 80$ equivalents of DiSeL tag 8 to Sav-QDs, readily entered into the cytosol of insect cells (Figure $4 \mathrm{~A}$ ). DiSeLmediated uptake delivered $57 \pm 6$ QDs (mean \pm SEM, $n=20$ cells) which was comparable to results with CPDs. ${ }^{[5]}$ Compared to CPDs, higher ratios of DiSeL tag 8 were used, but the conjugates precipitated less. The motilities of thousands of QDs were categorized in three types by automatic tracking (Figure 4B): 1) short-range motion ( $79 \%$ of $n=8019$ tracks over $n=13$ cells), 2 ) long-range motion (6 tracks only) and 3 ) immobility. The Mean Square Displacement (MSD) analysis of the QDs in short-range

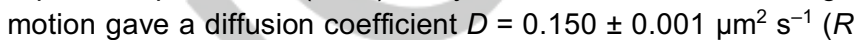
$=0.998 ; \alpha=0.627 \pm 0.016 ; 95 \%$ confidence interval). Such subdiffusion with a confined motility behavior is characteristic for QDs delivered in the cytosol. ${ }^{[5,25]}$ These results thus suggested that DiSeL mediates the delivery of QDs to the cytosol with 79\% efficiency with little endosomal capture $(0.06 \%)$ and, compared to CPDs reduced precipitation and immobilization on the cell surface (20\% in total)

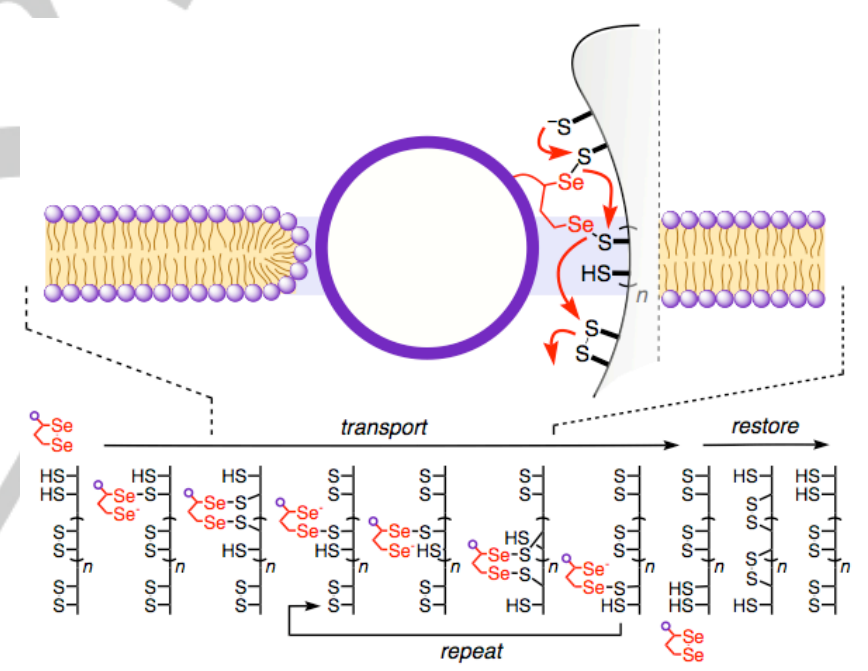

Figure 5. A working hypothesis for the mode of action of DiSeL-mediated uptake, focusing on dynamic covalent dichalcogenide exchange cascades to walk along disulfide tracks in a membrane protein (right, grey), with a large substrate (purple circle) carried moving through an adaptive micellar membrane defect (left)

Concerning the mode of action, the diversity of delivered substrates makes trivial changes in physical properties, such as increased hydrophobicity to favorize passive diffusion, unlikely to account for DiSeL-mediated uptake. Insensitivity to standard inhibitors and negligible endosomal capture disfavors uptake by different forms of endocytosis. ${ }^{[11]}$ A tentative mode of action considers that rapid opening of the diselenolane with an exofacial thiol produces a selenolate that remains deprotonated even under slightly acidic conditions (Figure 5). Exchange of this reactive selenolate initiates a molecular walk ${ }^{[15]}$ along disulfide tracks across the membrane, causing temporary protein denaturation ${ }^{[16]}$ on one side and the temporary appearance of adaptive, non-leaky 
and self-healing micellar defects ${ }^{[17]}$ on the other side, thus assuring compatibility with the translocation of substrates of variable, even very large size (Figure 5). Release into the cytosol is conceivable by favorable ring closure ${ }^{[11]}$ or by exchange with glutathione. ${ }^{[1,2]}$ Needed for continuing transport (and function), the initial redox state of the membrane protein can be readily restored by reverse thiol/disulfide exchange cascades. This working hypothesis is compatible with extensive model studies, including poor retention on thiol-affinity columns ${ }^{[11]}$ and trapping of reactive intermediates. ${ }^{[26]}$ A striking similarity with the repair of misfolded protein with diselenides further supports the walker hypothesis because this catalytic process has been studied in detail and shown to occur also in vivo. ${ }^{[16]}$

However, independent of the mode of action, the superb substrate scope identified in this study together with the small size, synthetic accessibility, stability, solubility, low toxicity and high efficiency promise that diselenolane-mediated cellular uptake could become quite useful in practice. Particularly interesting is the efficient cytosolic delivery of two orders of magnitude larger substrates like protein-coated quantum dots (diameter $\sim 15 \mathrm{~nm}$ ) by the miniscule diselenolanes (diameter $\sim 0.3 \mathrm{~nm}$ ), a stunning disproportion that is reminiscent of the ant carrying the elephant.

\section{Acknowledgements}

We thank F. Schwizer for providing the ruthenium complex 20, J. López-Andarias, E. Derivery and the Roux group for assistance with cell culture, the NMR, the MS and the Bioimaging platforms for services, and the University of Geneva, the Swiss National Centre of Competence in Research (NCCR) Chemical Biology, the NCCR Molecular Systems Engineering and the Swiss NSF for financial support. YO acknowledges a JSPS Overseas research fellowship.

Keywords: cellular uptake $\cdot$ diselenolane $\cdot$ ring tension $\cdot$ protein delivery $\bullet$ streptavidin-biotin biotechnology

[1] a) S. Aubry, F. Burlina, E. Dupont, D. Delaroche, A. Juliot, S. Laveille, G Chassaing, S. Sagan, FASEB J. 2009, 23, 2956-2967; b) D. Oupický, J. Li, Macromol. Biosci. 2014, 14, 908-922; c) T. Li, W. Gao, J. Liang, M. Zha, Y. Chen, Y. Zhao, C. Wu, Anal. Chem. 2017, 89, 8501-8508; d) X. Meng, T. Li, Y. Zhao, C. Wu, ACS Chem. Biol., in press, DOl: 10.1021/acschembio.8b00564; e) A. G. Torres, M. J. Gait, Trends Biotechnol. 2012, 30, 185-190; f) P. K. Hashim, K. Okuro, S. Sasaki, Y. Hoashi, T. Aida, J. Am. Chem. Soc. 2015, 137, 15608-15611; g) S. A Bode, R. Wallbrecher, R. Brock, J. C. M. van Hest, D. W. P. M. Löwik, Chem. Commun. 2014, 50, 415-417; h) C. R. Drake, A. Aissaoui, O Argyros, M. Thanou, J. H. G. Steinke, A. D. Miller, J. Control. Release 2013, 171, 81-90; i) D. Jha, R. Mishra, S. Gottschalk, K.-H. Wiesmüller, K. Ugurbil, M. E. Maier, J. Engelmann, Bioconjugate Chem. 2011, 22, 319-328.

[2] a) H. Xu, W. Cao, X. Zhang, Acc. Chem. Res. 2013, 46, 1647-1658; b) C. C. Tjin, K. D. Otley, T. D. Baguley, P. Kurup, J. Xu, A. C. Nairn, P. J. Lombroso, J. A. Ellman, ACS Cent. Sci. 2017, 3, 1322-1328; c) Y. Wang, L. Zhu, Y. Wang, L. Li, Y. Lu, L. Shen, L. W. Zhang, ACS Appl. Mater. Interfaces 2016, 8, 35106-35113; d) C. Wei, Y. Zhang, Z. Song, Y. Xia, H. Xu, M. Lang, Biomater. Sci. 2017, 5, 669-677.

[3] a) C. J. McKinlay, R. M. Waymouth, P. A. Wender, J. Am. Chem. Soc. 2016, 138, 3510-3517; b) I. Lostalé-Seijo, I. Louzao, M. Juanes, J. Montenegro, Chem. Sci. 2017, 8, 7923-7931; c) J. Rodríguez, J. Mosquera, J. R. Couceiro, J. R. Nitschke, M. E. Vázquez, J. L. Mascareñas, J. Am. Chem. Soc. 2017, 139, 55-58; d) M. Grogg, D.
Hilvert, M. Ebert, A. Beck, D. Seebach, F. Kurth, P. Dittrich, C. Sparr, S. Wittlin, M. Rottmann, P. Mäser, Helv. Chim. Acta 2018, 101, e18000112.

[4] a) E.-K. Bang, G. Gasparini, G. Molinard, A. Roux, N. Sakai, S. Matile, J. Am. Chem. Soc. 2013, 135, 2088-2091; b) G. Gasparini, E.-K. Bang, G. Molinard, D. V. Tulumello, S. Ward, S. O. Kelley, A. Roux, N. Sakai, S Matile, J. Am. Chem. Soc. 2014, 136, 6069-6074; c) P. Morelli, S. Matile, Helv. Chim. Acta 2017, 100, e1600370; d) P. Morelli, E. Bartolami, N. Sakai, S. Matile, Helv. Chim. Acta 2018, 101, e1700266.

[5] E. Derivery, E. Bartolami, S. Matile, M. Gonzalez-Gaitan, J. Am. Chem. Soc. 2017, 139, 10172-10175.

[6] a) Y. Okamoto, R. Kojima, F. Schwizer, E. Bartolami, T. Heinisch, S. Matile, M. Fussenegger, T. R. Ward, Nat. Commun. 2018, 9, 1943; b) T. Heinisch, F. Schwizer, B. Garabedian, E. Csibra, M. Jeschek, J. Vallapurackal, V. B. Pinheiro, P. Marlière, S. Panke, T. R. Ward, Chem. Sci. 2018, 9, 5383-5388.

[7] a) L. Qian, J. Fu, P. Yuan, S. Du, W. Huang, L. Li, S. Q. Yao, Angew. Chem. Int. Ed. 2018, 57, 1532-1536; Angew. Chem. 2018, 130, 15481552; b) S. Du, S. S. Liew, L. Li, S. Q. Yao, J. Am. Chem. Soc. 2018, 140, 15986-15996.

[8] a) C. Wang, M. R. Krause, S. L. Regen, J. Am. Chem. Soc. 2015, 137, 664-666; b) H. Y. Au-Yeung, F. B. L. Cougnon, S. Otto, G. D. Pantoş, J. K. M. Sanders, Chem. Sci. 2010, 1, 567-574.

[9] G. Gasparini, G. Sargsyan, E.-K. Bang, N. Sakai, S. Matile, Angew. Chem. Int. Ed. 2015, 54, 7328-7331; Angew. Chem. 2015, 127, 74367439 .

[10] L. Zong, E. Bartolami, D. Abegg, A. Adibekian, N. Sakai, S. Matile, ACS Cent. Sci. 2017, 3, 449-453.

[11] N. Chuard, A. I. Poblador-Bahamonde, L. Zong, E. Bartolami, J. Hiltebrandt, W. Weigand, N. Sakai, S. Matile, Chem. Sci. 2018, 9, 18601866 .

[12] a) A. D. Clauss, S. F. Nelsen, M. Ayoub, J. W. Moore, C. R. Landis, F. Weinhold, Chem. Educ. Res. Pract. 2014, 15, 417-434; b) P. C. Hiberty, B. Braïda, Angew. Chem. Int. Ed. 2018, 57, 5994-6002; Angew. Chem. 2018, 130, 6100-6109.

[13] a) J. Hildebrandt, T. Niksch, R. Trautwein, N. Häfner, H. Görls, M.-C. Barth, M. Dürst, I. B. Runnebaum, W. Weigand, Phosphorus Sulfur Silicon Relat. Elem. 2017, 192, 182-186; b) D. Steinmann, T. Nauser, W. H. Koppenol, J. Org. Chem. 2010, 75, 6696-6699; c) W. H. H. Guenther, J. Org. Chem. 1967, 32, 3931-3933; d) J. Beld, K. J. Woycechowsky, D. Hilvert, Biochemistry, 2008, 47, 6985-6987; e) J. C. Lukesh, B. VanVeller, R. T. Raines, Angew. Chem. Int. Ed. 2013, 52, 12901-12904; Angew. Chem. 2013, 125, 13139-13142.

[14] a) D. Abegg, G. Gasparini, D. G. Hoch, A. Shuster, E. Bartolami, S. Matile, A. Adibekian, J. Am. Chem. Soc. 2017, 139, 231-238; b) N. Chuard, G. Gasparini, D. Moreau, S. Lörcher, C. Palivan, W. Meier, N. Sakai, S. Matile, Angew. Chem. Int. Ed. 2017, 56, 2947-2950; Angew. Chem. 2017, 129, 2993-2996.

[15] a) A. G. Campaña, D. A. Leigh, U. Lewandowska, J. Am. Chem. Soc 2013, 135, 8639-8645; b) M. J. Barrell, A. G. Campaña, M. von Delius, E. M. Geertsema, D. A. Leigh, Angew. Chem. Int. Ed. 2011, 50, 285-290; Angew. Chem. 2011, 123, 299-304; c) J.-S. Shin, N. A. Pierce, J. Am. Chem. Soc. 2004, 126, 10834-10835; d) K. Lund, A. J. Manzo, N. Dabby, N. Michelotti, A. Johnson-Buck, J. Nangreave, S. Taylor, R. Pei, M. N. Stojanovic, N. G. Walter, E. Winfree, H. Yan, Nature 2010, 465, 206-210; e) H. D. F. Winkler, D. P. Weimann, A. Springer, C. A. Schalley, Angew. Chem. Int. Ed. 2009, 48, 7246-7250; Angew. Chem. 2009, 121, 73827386.

[16] a) N. Metanis, D. Hilvert, Chem. Sci. 2015, 6, 322-325; b) J. Beld, K. Woycechowsky, D. Hilvert, ACS Chem. Biol. 2010, 5, 177-182; c) S. Shimodaira, Y. Asano, K. Arai, M. Iwaoka, Biochemistry 2017, 56, 5644-5653.

[17] G. Gasparini, E.-K. Bang, J. Montenegro, S. Matile, Chem. Commun 2015, 51, 10389-10402.

[18] See SI.

[19] a) M. Fairhead, D. Krndija, E. D. Lowe, M. Howarth, J. Mol. Biol. 2014, 426, 199-214; b) G. V. Dubacheva, C. Araya-Callis, A. G. Volbeda, M Fairhead, J. Codée, M. Howarth, R. P. Richter, J. Am. Chem. Soc. 2017, 139, 4157-4167.

[20] J. R. Peterson, T. J. Mitchison, Chem. Biol. 2002, 9, 1275-1285. 
[21] M. P. Raphael, C. A. Rappole, L. K. Kurihara, J. A. Christodoulides, S. N. Qadri, J. M. Byers, J. Fluoresc. 2011, 21, 647-652.

[22] R. M. Yusop, A. Unciti-Broceta, E. M. V. Johansson, R. M. SánchezMartín, M. Bradley, Nat. Chem. 2011, 3, 239-243.

[23] a) V. Jeannot, J.-M. Salmon, M. Deumié, P. Viallet, J. Histochem. Cytochem. 1997, 45, 403-412; b) M. M. Pires, J. Chmielewski, Org. Lett. 2008, 10, 837-840.

[24] S. Wilhelm, A. J. Tavares, Q. Dai, S. Ohta, J. Audet, H. F. Dvorak, W. C. W. Chan, Nat. Rev. Mater. 2016, 1, 16014.

[25] a) H. Hatakeyama, Y. Nakahata, H. Yarimizu, M. Kanzaki, Mol. Biol. Cell 2017, 28, 173-181; b) E. A. Katrukha, M. Mikhaylova, H. X. van Brakel, P. M. van Bergen en Henegouwen, A. Akhmanova, C. C. Hoogenraad, L. C. Kapitein, Nat. Commun. 2017, 8, 14772; c) S. Courty, C. Luccardini, Y. Bellaiche, G. Cappello, M. Dahan, Nano Lett. 2006, 6, 1491-1495.

[26] Q. Laurent, N. Sakai, S. Matile, Helv. Chim. Acta, 2019, in press, $10.1002 /$ hlca.201800209 
Key Topic: Cellular Uptake

\section{COMMUNICATION}

The ant and the elephant:

Compatibility with a variety of large substrates of biological relevance is reported to

substantiate the power and promise of the tiny diselenolanes to enter cells by a cascade of fast and selective dynamic covalent dichalcogenide exchange reactions.

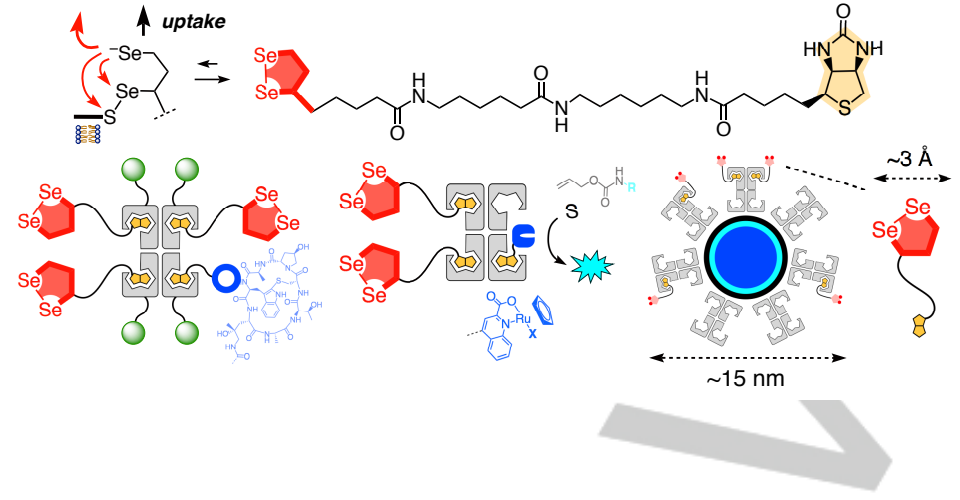

E. Bartolami, $D$.

Basagiannis, L. Zong,

R. Martinent, $Y$.

Okamoto, Q. Laurent, T. R. Ward, M.

Gonzalez-Gaitan, N.

Sakai and S. Matile*

Page No. - Page No.

Diselenolane-Mediated

Cellular Uptake:

Efficient Cytosolic

Delivery of Probes,

Peptides, Proteins,

Artificial

Metalloenzymes and

Protein-Coated

Quantum Dots 